\title{
One-Sided Advertising: How Does It Overcome Consumer Resistance?
}

\author{
Han-Kuang Tien ${ }^{1}$, Yueh-Hsia Huang ${ }^{1}$, Siao-Yun Wei ${ }^{2}$, Yung-Yen Chen ${ }^{1}$, Tyng-Bin Ger $^{3} \&$ Yen-Lin Kuo ${ }^{4}$ \\ ${ }^{1}$ Department of International Trade, Chinese Culture University, Taipei, Taiwan \\ ${ }^{2}$ Department of Banking and Finance, Chinese Culture University, Taipei, Taiwan \\ ${ }^{3}$ Department of Information Management, Minghsin University of Science and Technology, Hsinchu, Taiwan \\ ${ }^{4}$ Bachelor Program of Digital Media, Chinese Culture University, Taipei, Taiwan \\ Correspondence: Han-Kuang Tien, Department of International Trade, School of Business, Chinese Culture \\ University, No. 231, Sec. 2, Chien-Kuo S. Rd., Taipei, Taiwan.
}

Received: January 16, 2022

doi:10.5539/ijms.v14n1p46
Accepted: February 22, 2022

Online Published: February 27, 2022

URL: https://doi.org/10.5539/ijms.v14n1p46

\begin{abstract}
This study explores how to enhance the effectiveness of one-sided advertising based on time-connectedness theory, especially for products resisted by customers. If managers can find a way to persuade consumers who initially reject a product or a service, they can improve one-sided advertising effectiveness. This study uses cognitive association to help connect the current self of participants with their temporal self, which it was hypothesized could help change their initial negative attitude. This hypothesis was verified through two studies, involving 335 and 312 student participants respectively. We found that participants changed initial negative attitude after exposure to time-connected advertising. This change was influenced by their need for cognition (NFC) - individuals with high NFC were more likely to be persuaded (to develop a more positive attitude toward advertising) through role transportation. As for individuals with low NFC, initial negative attitude among them was less likely to change through role transportation. The findings indicate to best reduce audience resistance and enhance advertising effectiveness, that marketing personnel need to know whether the audience's (initial) attitude toward a product or service is negative or positive before selecting or developing advertising appeals.
\end{abstract}

Keywords: resistance, persuasion theory, time-connectedness theory, one-sided advertising, need for cognition

\section{Introduction}

When an advertisement from a manufacturer or a sales representative on a shop floor gives a persuasive suggestion or information that may change one's attitude, the words "Well, perhaps, but..." may cross one's mind; in that case, persuasion resistance has appeared (Knowles \& Linn, 2004). Traditionally, sales representatives often provide information useful to themselves when trying to convince consumers (Eisend, 2006; 2010); similarly, the majority of advertisements provide one-sided information that is helpful to manufacturers. The goal of advertisements that provide one-sided information is to foster a positive attitude towards this brand or service in the target audience. However, from the perspective of resistance theory, classical theories about advertising appeals such as the elaboration likelihood model (ELM) (Petty, Cacioppo, \& Schumann 1983; Petty Cacioppo, Strathman, \& Priester, 2005) and expert endorsement (the central route to persuasion) can also evoke resistance (Tormala \& Petty, 2002, 2004), as consumers (may) take an initial negative attitude during communication.

Previous research thus advocates two-sided advertising (providing both advantageous and adverse information) as a way to overcome an initial negative attitude towards certain products (Ertz, Jo, Karakas, \& Sarigöllü, 2021; Schmitt, Caspari, Wulf, Bloch, \& Rieger, 2021). Research results show that the provision of advantageous and adverse information about the products improves source reliability, consumers' attitude towards the products, and their willingness to buy products (Crowley \& Hoyer, 1994; Eisend, 2006, 2010; Xu \& Petty, 2021). One explanation of the functioning of two-sided messages is given by attribution theory: consumers explain to themselves the causes of behaviors and events during persuasion (partly) by assuming that advertisements are what manufacturers say to sell the products. Thus, when there is adverse information about the products in the advertisements, consumers think that the manufacturers are telling the truth, since they would not lie to their 
detriment (Jones \& Davis, 1965; Jones \& McGillis, 1976). Another theory behind the effect of two-sided messages is provided by inoculation theory (McGuire, 1964). In this theory, a rebuttal argument, called a refutational appeal, is made by consumers resistant to a product and a two-sided message about it, and consumers will only be persuaded when they deliberate on both advantageous and adverse information. Here emerges a question. Is one-sided advertising unable to overcome negative attitudes among consumers?

Connectedness theory (Zhang \& Aggarwal, 2015), which is rooted in role transportation theory (Green \& Brock, 2000), provides one account of how one-sided advertising can overcome such resistance. In this account, the use of story-telling techniques immerses consumers in a desired context, changing their roles temporarily in a way that reduces their resistance to persuasion. In particular, time-connectedness theory (Zhang \& Aggarwal, 2015; Yang, Huang, Cai, Song, Jiang, Chen, \& Chen, 2021). suggests that a story can persuade by helping the audience connect their current self with their "temporal" (past or future) self through association (Saine, Nguye, Besharat, \& Trocchia, 2018). In other words, the theory makes the audience hold previous and future contextual associations on certain products, services, and time (Urminsky, 2017). For instance, a nostalgic ad may lead its audience to the happy time in the past, which inclines them to buy the product.

Previous studies show that information alone will not persuade people; a critical element is also the motivation of the individual processing the information. (Levin \& Gaeth, 1988). Cacioppo and Petty (1982) found that individuals with a high need for cognition (NFC) often analyze and ponder over the message that they receive or understand themselves to be meant to receive from the ad, while low-NFC individuals often do not. In this light, the communication effect of advertising is related to the cognition of the target audience. Therefore, this study adopts the NFC level of the target audience as the moderating variable, to explore the persuasiveness of different advertising appeals for those who have different NFC levels.

The two case studies taken up here respectively look at English learning and volunteering services in Taiwan, to which participants are resistant. Regarding the former case, a majority of Taiwanese students are not highly motivated to learn English and the private schools that provide remedial English classes fail to persuade them to enroll through advertising. The second case study is on campus volunteer recruitment, because many Taiwanese college students are reluctant to participate in volunteering. Time-connectedness theory as per Zhang and Aggarwal (2015) informs the advertising appeals used in the case studies, in the hope that the target audience can be transported to the context fostered by the advertising: transported into a role that enhances the effectiveness of advertising by reducing their resistance to the product. Since the target audience may put different interpretations on the same advertising, NFC is used as a moderating variable to examine whether the NFC levels of the target audience affect the way they process information in the advertising appeals from the perspective of time-connectedness theory. On the basis of the findings, this study offers suggestions for advertising agencies.

\section{Literature Review and Hypotheses}

\subsection{Resistance Theory}

It is common knowledge or common sense that people have the freedom to have their own attitudes toward things. When this freedom is limited or threatened, resistance occurs. People often perceive their freedom to be thus limited when persuasive information in advertising is conveyed to them in the hopes of shaping their choices; in this case, they resist the information (Knowles \& Linn, 2004; Sagarin \& Serna, 2002). Resistance theory and previous studies on persuasive advertising claim that when people remain resistant to the product or service, they successfully resist persuasion in advertising, and no negative impact will be produced. However, recent studies point out that the confidence of the target audience may be boosted when they successfully resist persuasion (Kamarkar \& Tormala, 2010; Tormala \& Petty, 2002, 2004); that is, certain after-effects may be produced because of the resistance and these effects may even influence the persuaders (Banas \& Miller, 2013).

\subsection{Persuasion Theory}

Previous literature advises marketers to address consumers' negative attitudes towards given products with two-sided messages, based on both attribution theory and inoculation theory (Eisend \& Tarrahi, 2022). The former theory reveals that consumers tend to think that the advertiser tells the truth when there is negative information in the advertisement; this improvement in perceived source reliability will be improved, which reduces consumer resistance (Jones \& Davis, 1965; Jones \& McGillis, 1976). As for inoculation theory, in the context of advertising research, the theory applies when an enterprise experiences business crises or attacks from its competitors if it continuously plays image advertisements, as its target consumers have already had a "vaccine" against the attacks, which decreases the harm brought by the attacks (Banas \& Rains, 2010; Kim, 2012; Szybillo \& Heslin, 1973). Theories that mean to resolve the problem of consumer resistance toward certain products must manage to persuade consumers by both providing information for them to deliberate and 
reducing their resistance to the information and the product.

A method based on the elicitation of emotions is also helpful in reducing consumers' resistance towards certain products, especially with one-sided messages. Strick, Holland, van Baaren, and van Knippenberg (2012) proposed that humor in advertising can reduce resistance by preventing consumers from connecting the negative information with the brand of the advertised product (Blanc \& Brigaud, 2014). However, not all products or services are suited to use humor in their advertisements-for instance, funeral services. Another approach to reducing consumer resistance is the altercasting theory proposed by Weinstein and Deutschberger (1964), which points out that if one is invited to play a new social role one may take it up and follow its rules and values when interacting with people. That is to say, in this view society is a stage and social norms decide the script and lines of each role (Biddle, 1979; Koenig \& Eagly, 2014).

Narrative transportation is one important mode of role transportation, proposed by Green and Brock (2000), who claim that the mainstream theories about changing attitudes cannot establish persuasive mechanisms based on a narrative, but instead that narrative transportation is a special persuasion route: that sorrowful plots used in narrative advertising immerse the target audience in the story in order to temporarily change their roles (Green \& Fitzgerald, 2017; Volkman, 2017).

Narrative transportation consists of two parts: a story and immersion in that story. Green and Brock (2000) posit that a story is expected to achieve certain effects - for instance, to make the audience feel that there is an unanswered question, an unresolved mental conflict, or an unfinished description. Generally speaking, the protagonist in a story has a problem. For example, in the advertising used in the research, a baby-sitter goes shopping with a child, but a patient who has escaped from a mental asylum murders them.

Narrative transportation means that one will be immersed in the story unconsciously because of the emotion evoked by the plot. Phillips and McQuarrie (2010) indicate that narrative transportation includes three basic elements: a story that provides a setting, an experience in which one is totally immersed in the plot and forgets the real world, and the change that one makes after one watches the story.

Green and Brock (2000) applied the narrative technique in their study, endeavoring to construct a story that would immerse the target audience and transport them into the context of the advertising through a narrative to persuade them thereby. Phillips and McQuarrie (2010) proposed that immersion leads to a strong sense that the world described in the advertising is real, whereas on the other hand if the target audience assess, judge, and doubt the information they receive, the advertising is less likely to succeed in transporting them to its context. Cin, Zanna and Fong (2004) further illustrate that an effective narrative can help advertisers reduce resistance to persuasion by engendering transference, or empathetic identification with the misfortunes of characters, and thereby discouraging logical analysis of messages on the audience's part.

\subsection{Time-Connectedness Theory}

Emotions are the outcome of daily experiences (Hirsch 1992; Richins, 1997). The most commonly used persuasive strategy in advertising is nostalgia; contrasting that approach, however, Zhang and Aggarwal (2015) proposed a new persuasive strategy of "time-connected transportation," which uses a "time travel" technique to trigger the audience's associations with the future as a persuasive mechanism. Specifically, imagining the positive affordance of having or using the product or service in the future will indirectly foster the inclination to buy it. They also (re)assert the persuasive importance of immersion, and of circumventing doubt or critical thinking, in the time-connected context.

On this basis, the present study proposes its first hypothesis as follows:

H1: A target audience who are initially resistant to certain products or services may be persuaded after watching time-connected advertising.

\subsection{The Need for Cognition}

Varying levels of need for cognition result from different ways of processing information. High-NFC individuals often spend much time assessing persuasive information in order to understand and selectively accept or reject it, while low-NFC individuals are more likely to be influenced by the people and things in the advertising (Haugtvedt, Petty, \& Cacioppo, 1992; Haugtvedt \& Petty, 1992; Petty \& Cacioppo, 1986). As this implies, low-NFC individuals are more straightforwardly influenceable.

The present study explores whether different NFC levels of an audience affect their attitude toward a product or service in the time-connected context and the communication effect of time-connected advertising. To do so, the study proposes its second hypothesis, in two parts, as follows: 
H2a: A target audience with lower NFC and initial resistance toward certain products and services is more likely to be persuaded by time-connectedness.

$\mathrm{H} 2 \mathrm{~b}$ : A target audience with higher NFC and initial resistance toward certain products and services is less likely to be persuaded by time-connectedness.

\subsection{Advertising Effectiveness}

\section{Effectiveness of persuasion}

As noted, this study measures the communication effect of time-connected advertising, and the willingness of a target audience to learn about a product or a service before and after they watch the advertising, and determine differences in their willingness and therefore the success of persuasion across NFC groups.

\section{Research Design}

\subsection{Study One}

English learning is chosen as the advertising topic in the first case study, because many Taiwanese students lack motivation to learn English, and advertising for English tutorial classes does not often persuade the target audience to learn English. In this study, time-connectedness theory was applied to English class advertising to see whether time-connectedness helps reduce resistance and enhance advertising effectiveness.

In this study, the independent variable is time-connectedness of advertising, while the moderating variable is NFC. Before the experiment, the participants were randomly divided into two groups: the "resistant to English learning" group and the "willing to learn English" group. To ensure the accuracy of the experimental results, each participant watched only one advertising appeal and completed the corresponding questionnaires.

\subsection{Manipulation Check}

A pilot test was carried out to examine whether the participants could distinguish whether the ad represented the current or temporal self of the character represented in the ad and whether time-connectedness in the ad helps reduce resistance to it.

This study recruited 20 college students to participate in the pilot test. They were randomly divided into two groups. The first group watched a time-connected video ad for an English school created for this experiment. The second group watched a non-time-connected video. Then, students in both groups filled in a questionnaire using a seven-point Likert-type scale, asking them to rate the ad in terms of various items related and unrelated to time-connectedness.

Analysis of variance (ANOVA) was used to test whether the participants were able to distinguish the character as represented in the video they watched as having a current or temporal self. The findings showed that participants who watched the non-time-connected ad scored the ad higher on items unrelated to time-connectedness than those who watched the time-connected ad $(\mathrm{M}$ non-time-connectedness $=4.60, \quad \mathrm{SD}=0.810, \mathrm{M}$ time-connectedness $=3.70, \mathrm{SD}=1.160, \mathrm{~F}(1,18)=4.050, \mathrm{p}=0.059<0.01)$, while participants who watched the time-connected ad scored it higher on items related to time-connectedness $(\mathrm{M}$ non-time-connectedness $=2.30$, $\mathrm{SD}=1.033, \mathrm{M}$ time-connectedness $=9.40, \mathrm{SD}=1.838, \mathrm{~F}(1,18)=113.423, \mathrm{p}=0.000<0.01)$. This indicates that the pilot participants perceived the two videos differently in terms of time-connectedness, and so the manipulation would be effective.

\subsection{The Experiment}

In total, 335 participants (college students) participated in the experiment. They were randomly divided into two groups: the first group watched a time-connected advertising video while the other group watched a non-time-connected advertising video. Before watching the videos, the participants were asked to answer questionnaires that measured their attitude toward English learning, and after completing the videos, they were asked to answer another questionnaire that measured the ad's effectiveness. A seven-point Likert-type scale was used in the questionnaires to help spot the changes in their attitude toward English learning before and after watching the videos.

Based on the pre-questionnaire results, the top and bottom $27 \%$ of scores were categorized as the "willing to learn English" group $(\mathrm{n}=127)$ and the "resistant to learning English" group $(\mathrm{n}=93)$, respectively. In the videos, a fictitious brand, Eason English Language School, was used to avoid possible interference from existing perceptions of a real brand.

The pre-questionnaire measured three dimensions: individual willingness to learn English, personal English-learning habits, and NFC. The post-questionnaire measured one dimension: individual willingness to 
learn English. It also collected basic information for the participants.

\subsection{Manipulation of Independent Variables}

Time-connectedness

The difference between the advertising videos lay in their time-connectedness. The time-connected video was intended to act as a stimulus to induce the audience to ponder the information in the ad and form a contextual association: learning English will have a positive impact on their future if they start doing it now. This association with a future effect was then meant to lead them to reduce their resistance toward the product. The video that did not use time-connectedness showed the benefits of English learning without focusing explicitly on the future.

To control other variables that might influence the experimental results, both videos used the same color and background music and were the same length.

Need for cognition

The 18 items on NFC were adopted from the scale developed by Cacioppo, Petty, and Kao (1984), and used a seven-point Likert-type scale. To avoid influence of extrema, an overall median was calculated and used as a threshold for NFC levels (high or low).

Learning habits

Items were adopted from the Learning Habit Scale developed by Lin and Huang (2009) in a study on English learning among college students. The scale consists of six items measured on a seven-point Likert-type scale. The top and the bottom $27 \%$ of the scores are categorized into the high and the low score groups, respectively.

\subsection{Measurement of Dependent Variables}

\section{Effectiveness of persuasion}

This section measures changes in the participants' attitudes toward the product from before to after watching the videos. The changes were used to analyze the effectiveness of persuasion.

\subsection{Experimental Results and Analysis}

Descriptive statistics of the participants

The study recruited 335 participants; 127 (37.9\%) were men and 208 (62.1\%) were women.

Table 1. Information on participants (study one)

\begin{tabular}{llll}
\hline Items & High NFC & Low NFC & Total \\
\hline Resistant to Learning English Group (93 participants) & & & \\
$\quad$ Time-connected video & 18 & 23 & 41 \\
$\quad$ Non-time-connected video & 19 & 33 & 52 \\
Willing to Learn English Group (127 participants) & & & \\
$\quad$ Time-connected video & 26 & 30 & 56 \\
$\quad$ Non-time-connected video & 23 & 48 & 71 \\
\hline
\end{tabular}

Reliability analysis

Nunnally (1978) suggests that there is a high degree of internal consistency if Cronbach's $\alpha$ exceeds 0.7 -as all coefficients did in this study, as shown in Table 2.

Table 2. Reliability analysis (study one)

\begin{tabular}{lll}
\hline Scale & Cronbach's $\alpha$ & Number of Items \\
\hline Need for Cognition & 0.85 & 18 \\
English Learning Habits & 0.88 & 6 \\
Willingness to Learn English (before watching the videos) & 0.82 & 2 \\
Willingness to Learn English (after watching the videos) & 0.75 & 2 \\
\hline
\end{tabular}

ANOVA was used to test hypothesis 1. Advertising effectiveness (willingness to learn English after watching the videos minus willingness to learn English before watching the videos) was analyzed to understand whether 
changes in attitude toward the product were significant.

In the English-resistant group, the findings show a significant difference in English learning attitude after as against before watching the time-connected video $(\mathrm{M}$ time-connectedness $=3.2024, \mathrm{SD}=1.254, \mathrm{M}$ non-time-connectedness $=0.5686, \mathrm{SD}=1.284, \mathrm{~F}(1,91)=98.877, \mathrm{p}=0.000<0.05)$. These data show that the willingness of participants to learn English was improved more in those who watched the time-connected ad than in those who watched the non-time-connected ad.

These results are contrary to the hypotheses for this group that initially displayed low willingness to learn English. This finding is also not in line with the ELM, since that model suggests that those with high NFC are more likely to be persuaded by the central route of persuasion (i.e., strong arguments), whereas the findings of this study show that high-NFC individuals who have an initial negative attitude are persuaded by the peripheral route of persuasion (time-connected advertising) instead of the central one, as shown in Figure 1. Therefore, hypotheses $2 \mathrm{a}$ and $2 \mathrm{~b}$ are also not supported.

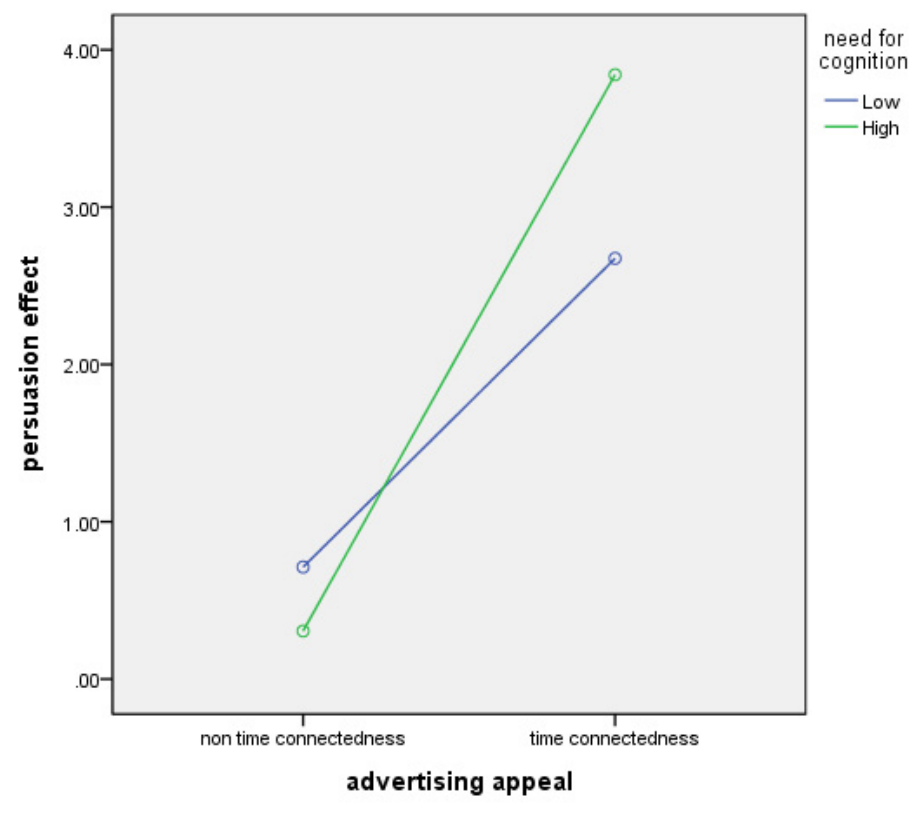

Figure 1. Interaction between NFC and persuasiveness for resistant to English learning group

To confirm the findings, the willing to learn English group was also analyzed using two-way ANOVA. It was found that those with low NFC in this group improved their willingness to learn English significantly after watching the time-connectedness video and this change reached a level of significance, as shown in Figure 2. 


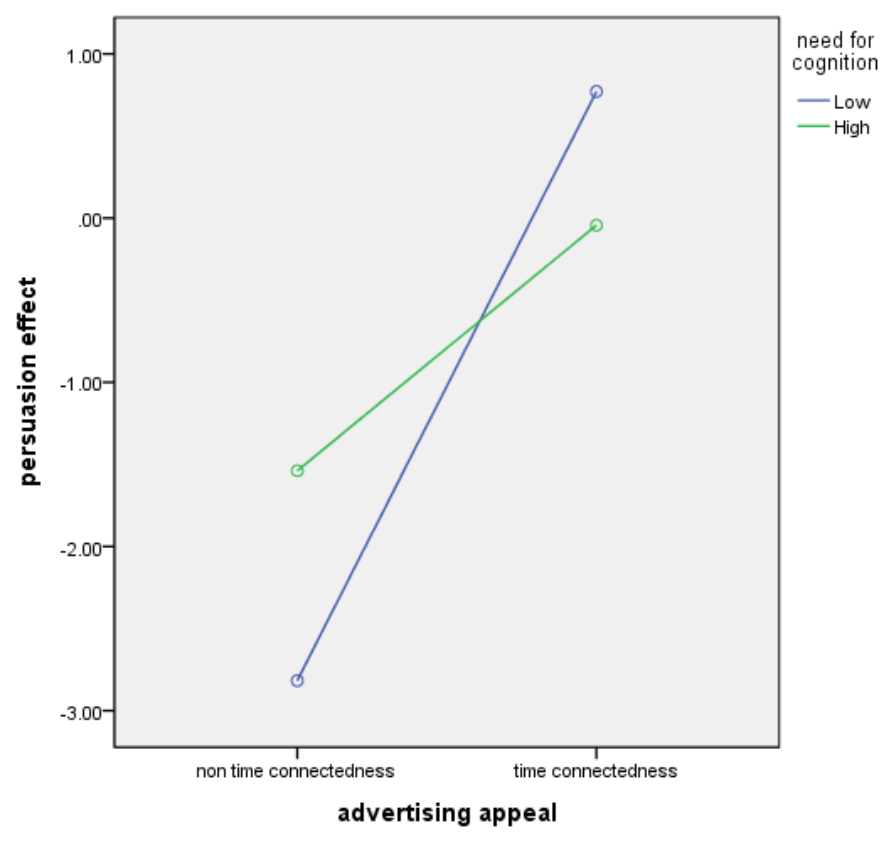

Figure 2. Interaction between NFC and persuasiveness for willing to learn English group

The comparison between the two groups indicates that the ELM works for participants who have an initial positive attitude toward a product but not those who have an initial negative attitude toward a product. That is, initial attitude toward a product is a key factor because it decides which persuasive strategy is effective.

\subsection{Discussion}

This study finds that it is necessary to immerse the audience in advertising and form associations between their current and future selves, in order to help them connect the ad to their own needs. The altercasting theory proposed by Weinstein and Deutschberger (1964) points out that one will interact based on the norms of a new social role that he or she is invited to play and make decisions based on the values associated with that role. In this light, time-connected advertising involves altercasting that transports the audience from their current selves to their future selves as a way of reducing resistance to the product.

The NFC level of the consumer is the key factor that decides whether they will form an association with their future self. The experiment shows that those with high NFC tend to assess information provided by advertising, accept it, and change initial negative attitude toward the product or service on that basis.

The comparison between the two groups conducted in study one shows that the ELM works for those who have an initial positive attitude toward the product but not for those who have an initial negative attitude. Tormala and Petty (2002) suggest that a target audience who are initially resistant to a product or service may develop further psychological resistance if strong arguments are used to convince them, reinforcing their initial negative attitude. This shows the importance of the initial attitude of consumers toward a product or service in determining what persuasive strategy to use.

\subsection{Study Two}

The second case study is about advertising for on-campus volunteer recruitment. The first case study found that the peripheral route to persuasion was more effective for those with high NFC and an initial negative attitude toward a product. The second case study will verify this finding in a new context. In addition, a scale on role transportation was implemented to examine whether those with high NFC in the resistant group had a higher level of immersion than those with low NFC.

\subsection{Pilot Test}

Twenty participants were recruited to participate in the pilot test. They were randomly divided into two groups: the first group watched a time-connected advertisement while the other watched a non-time-connected advertisement. Then, they answered a questionnaire using a seven-point Likert-type scale.

As in study one, ANOVA was adopted to ensure that the audience could distinguish the current or temporal self 
of the advertising character. The analysis shows that the participants who watched the non-time-connected video scored it on items unrelated to time-connected $(\mathrm{M}$ non-time-connectedness $=4.60, \mathrm{SD}=0.810, \mathrm{M}$ time-connectedness $=3.70, \mathrm{SD}=1.160, \mathrm{~F}(1,18)=4.050, \mathrm{p}=0.059<0.1)$, while participants who watched the time-connected ad scored it higher on time-connectedness ( $\mathrm{M}$ non-time-connectedness $=2.30, \mathrm{SD}=1.033, \mathrm{M}$ time-connectedness $=9.40, \mathrm{SD}=1.838, \mathrm{~F}(1,18)=113.423, \mathrm{p}=0.000<0.01)$. Thus, the videos were meaningfully different and the manipulation appropriate.

\subsection{The Experiment}

After the pilot was completed, 312 participants were recruited for the experiment. As in study one, they were divided into two random groups: the first group watched a time-connected advertisement about volunteering, while the other watched a non-time-connected advertisement. Before watching the videos, they were asked to fill in a questionnaire about their product attitude (the degree of their agreement on volunteering among college students), and again afterward, on a seven-point Likert-type scale. Thus, changes in their attitude toward volunteering — product attitude and advertising attitude — could be spotted.

The top and the bottom $27 \%$ of scores of agreement on volunteering from the pre-questionnaire, filled out by the participants before watching the videos, were used to define willing to volunteer $(\mathrm{n}=94)$ and resistant to volunteering $(\mathrm{n}=81)$ groups, respectively. A fictitious brand (Eason University) was again used in the videos to avoid interference resulting from pre-existing associations surrounding a real university, as in study one.

The pre-questionnaire consisted of two dimensions: attitudes toward volunteer recruitment and need for cognition. The post-questionnaire, in contrast, covered attitudes toward volunteer recruitment and degree of role transportation.

\subsection{Manipulation of Independent Variables}

\section{Time-connectedness}

Time-connected advertising imparts information to the audience by way of a metaphor. Time-connectedness acts as a stimulus to make the participant think about the information presented, forming an association between the current and the future self. The benefits of volunteering are thus conveyed to the current self by the future self, reducing resistance to volunteering.

In the non-time-connected video, a senior student who is a volunteer tells the audience about the benefits that she has obtained from volunteering on campus, in order to persuade them to take part in volunteering. To control other variables that may influence the experimental results, the two videos are the same in terms of color, background music, and length.

\subsection{Need for Cognition}

The NFC items again come from Cacioppo et al. (1984) and use a seven-point Likert-type scale. As in study 1, to avoid the impact of extrema, the overall mean was used as the benchmark for division of high- from low-NFC individuals.

\subsection{Role Transportation Effect}

Green and Brock (2000) developed 11 items to measure the role transportation effect; they were revised to fit this study.

\subsection{Measurement of Dependent Variables}

Effectiveness of persuasion

This section measures changes in the participants' attitudes toward the product (volunteer recruitment) from before to after they watched the videos. The changes were used to analyze the videos' respective persuasive effects.

\subsection{Experimental Result and Analysis}

Descriptive statistics of the participants

In total, 312 college students took part in the study; the two groups contained 175 members, out of which 60 $(34.3 \%)$ were men and 115 (65.7\%) were women. Detailed information on the group members is listed in Table 3. 
Table 3. Information on participants (study two)

\begin{tabular}{llll}
\hline Variable & High NFC & Low NFC & Total \\
\hline Resistant to Volunteering Group (81) & & & \\
Time-connected & 20 & 19 & 39 \\
$\quad$ Non-time-connected & 20 & 22 & 42 \\
Willing to Volunteer Group (94) & & & \\
Time-connected & 19 & 25 & 44 \\
Non-time-connected & 39 & 11 & 50 \\
\hline
\end{tabular}

Reliability analysis

As in study one, all coefficients of Cronbach's $\alpha$ exceeded 0.7, the threshold for high internal consistency given by Nunnally (1978); detailed information is listed in Table 4.

Table 4. Reliability analysis (study two)

\begin{tabular}{lll}
\hline Scale & Cronbach's $\alpha$ & $\begin{array}{l}\text { Number of } \\
\text { Items }\end{array}$ \\
\hline $\begin{array}{l}\text { NFC } \\
\begin{array}{l}\text { Product Attitude } \\
\text { (before) }\end{array}\end{array}$ & 0.74 & 18 \\
$\begin{array}{l}\text { Product Attitude } \\
\text { (after) }\end{array}$ & 0.91 & 6 \\
\hline
\end{tabular}

\subsection{One-Way ANOVA for the Resistant to Volunteering Group}

ANOVA was used to examine whether there were significant changes in attitude toward volunteer recruitment on campus and hence persuasiveness of advertising (measured by attitude after the experiment minus attitude before).

Those in the resistant to volunteering group who watched the time-connected video changed their attitude significantly more than those who watched the non-time-connectedness video ( $\mathrm{M}$ time-connectedness $=2.081$, $\mathrm{SD}=1.568, \mathrm{M}$ non-time-connectedness $=1.035, \mathrm{SD}=1.136, \mathrm{~F}(1,79)=11.931, \mathrm{p}=0.001<0.05)$.

In addition, the change in the attitude of members of the resistant to volunteering group reached a significant level for those who watched the time-connected video $(\mathrm{M}$ time-connectedness $=5.451, \mathrm{SD}=1.284, \mathrm{M}$ non-time-connectedness $=3.973, \mathrm{SD}=0.199, \mathrm{~F}(1,79)=52.27, \mathrm{p}=0.000<0.05)$.

\subsection{Two-Way ANOVA for the Resistant to Volunteering Group}

Two-way ANOVA was used to examine whether the NFC of the participants affected the persuasiveness of advertising. After watching the time-connected advertisement, those with high NFC had significantly higher agreement on the value of volunteering $(\mathrm{F}(3,79)=4.872, \mathrm{p}=0.030<0.05)$, as shown in Figure 3 . 


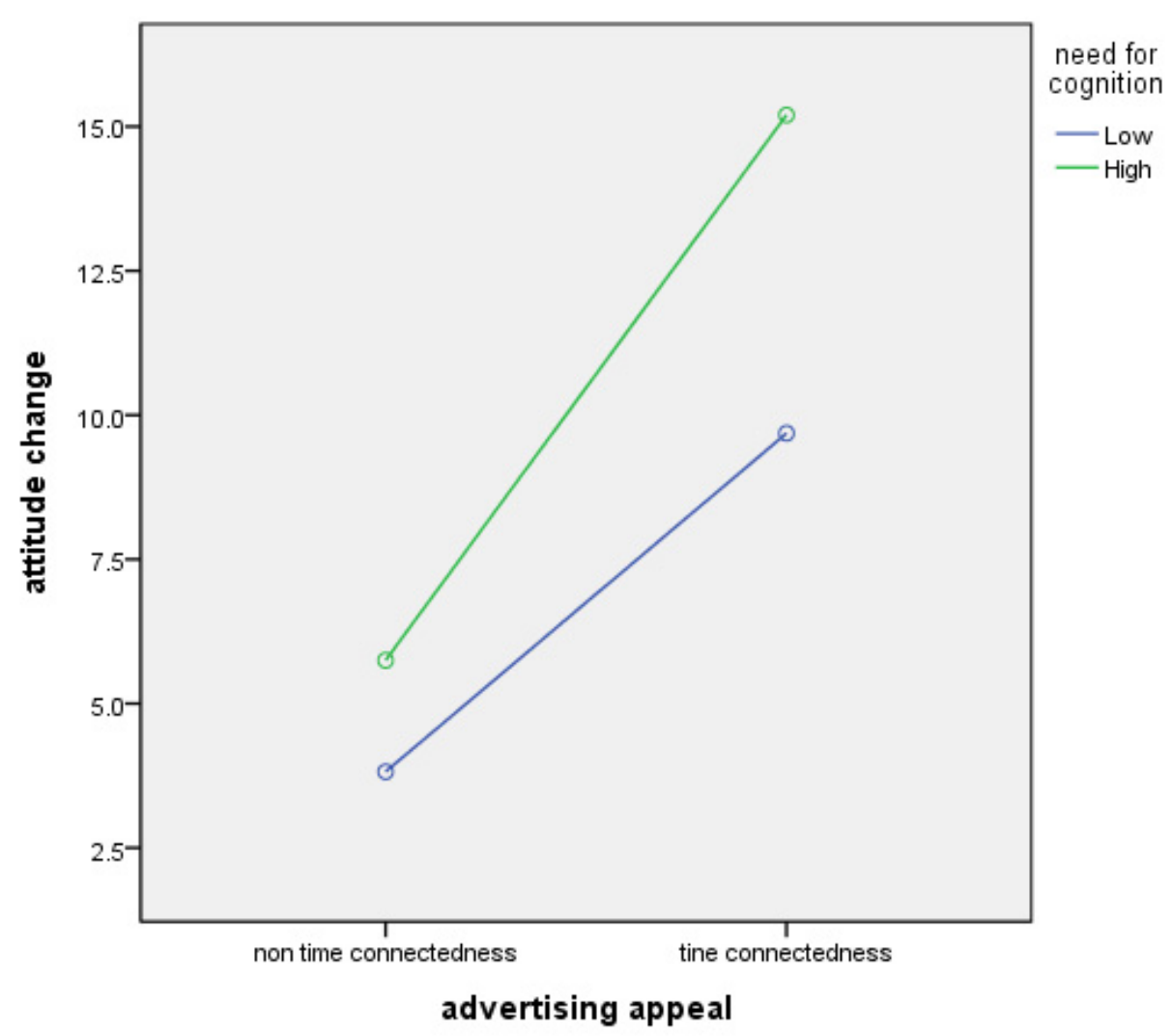

Figure 3. Interaction effect between advertising appeal and NFC

To further understand why those with high NFC who had an initial negative attitude toward campus volunteering showed a greater change in their attitude after watching the time-connected ad, degree of role transportation was set as a dependent variable, with time-connectedness and NFC were set as independent variables. These three variables were used to conduct two-way ANOVA. As seen in Table 8, high-NFC individuals who had an initial negative attitude toward volunteering experienced a higher degree of role transportation than did low-NFC individuals who also had an initial negative attitude $(F(3,77)=88.089, p=0.000<0.05)$. (See Figure 4). 


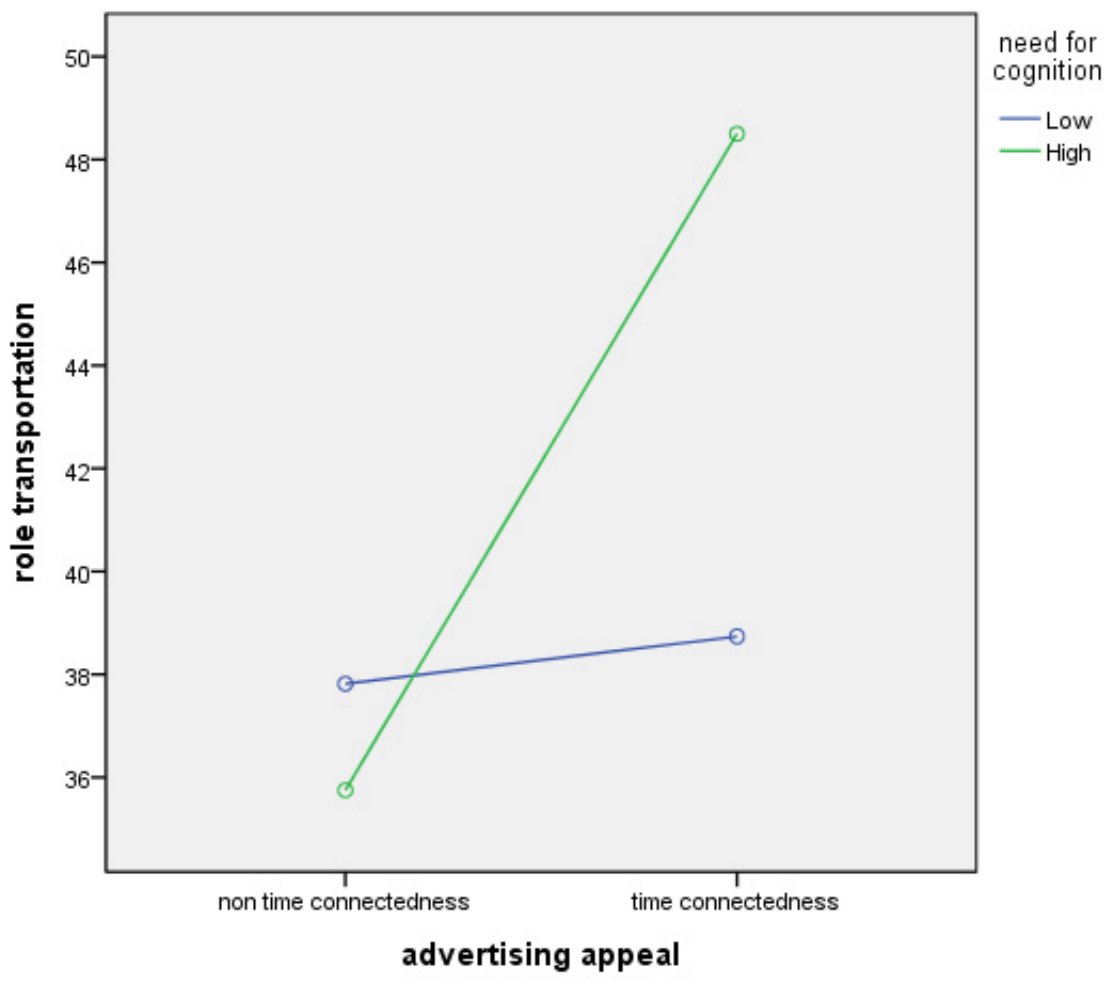

Figure 4. Interaction between advertising appeal and NFC

The willing to volunteer group scored high (positively) on attitude toward campus volunteer recruitment. Two-way showed that time-connectedness and NFC were not significantly correlated, F $(3,90)=2.459, \mathrm{p}=$ 0.120 , suggesting that time-connectedness and NFC (high vs. low) are not correlated.

\section{Conclusion}

\subsection{The Importance of Advertising Appeals}

Previous studies argue that two-sided advertising is the most effective way to reduce the resistance of consumers toward given products or services. Some scholars further suggest that resistance can also be reduced through one-sided advertising with the help of humor. However, humor cannot be used with all products and services; therefore, the present study supports the proposal time-connectedness theory can also be used to reduce resistance and improve the persuasiveness of ads. This is the study's most important contribution.

The experiments have shown that time-connected advertising (a form of one-sided advertising) can reduce the resistance of the audience to a certain product. For those who have an initial negative attitude toward a product, time-connected advertising immerses them and helps them temporarily put aside their resistance by transporting them to another time. In this way, the audience forms an association with a context in which they are more likely to accept the information, thereby enhancing the advertising's effectiveness. This may be useful for marketing products like pre-plan funeral contracts and insurance.

In addition, animated advertising works better than advertising that features real people - it is better at attracting attention and more memorable (Kuisma, Simola, Uusitalo, \& Oorni, 2010). The videos made for the case studies were all animated, so that this factor would not interfere with the experimental results.

\subsection{The Importance of Moderating Effects}

This study has shown that the NFC of consumers is a key factor in their response to ads that should affect advertisers' ad strategies and styles. Time-connected advertising in particular and the peripheral route in general are persuasive for high-NFC individuals who have an initial negative attitude toward a product; this is contrary to the ELM and the valorization of the central route, and reflects the established finding that strong arguments may lead to a firm, negative attitude (Tormala \& Petty, 2002); the ELM appears to hold in the case of a positive 
attitude toward a product, however.

\subsection{Suggestions for Future Research}

This study has adopted self-report scales to measure transference. However, emotions are a comprehensive response, including physiological reactions and brainwave changes, and future research should use other ways of measurement, such as brainwave sensors and emotion coding systems for micro-expressions. These methods of triangulation can more accurately determine emotional changes and verify the present findings.

Advertising generally includes plots, characters, background music, and various other elements. The videos made for this study were dull and low-quality compared to real ads. Future research could usefully adopt ads of a higher caliber. In addition, participants should be tested at the same time and place and in a realistic context.

Nowadays, online social networking is very popular. Social networking service users are likely to let out negative emotions aroused by given products or services, such as discontent, through those services; these emotions can then spread virally and give rise to resistant attitudes in their networks and more broadly. Therefore, it is worth studying how brand marketing managers can communicate effectively with potential consumers and reduce their resistance towards the products or services in the social networking context.

\section{References}

Banas, J. A., \& Miller, G. (2013). Inducing resistance to conspiracy theory propaganda: Testing inoculation and metainoculation strategies. Human Communication Research, 39, 184-207. https://doi.org/10.1111/hcre.12000

Banas, J. A., \& Rains, S. A. (2010). A meta-analysis of research on inoculation theory. Communication Monographs, 77(3), 281-311. https://doi.org/10.1080/03637751003758193

Biddle, B. J. (1979). Role theory: Expectations, identities, and behaviors. New York: Academic Press. https://doi.org/10.1016/B978-0-12-095950-1.50008-1

Blanc, N., \& Brigaud, E. (2014). Humor in print health advertisements: Enhanced attention, privileged recognition, and persuasiveness of preventive messages. Health Communication, 29, 669-677. https://doi.org/10.1080/10410236.2013.769832

Cacioppo, J. T., \& Petty, R. E. (1982). The need for cognition. Journal of Personality and Social Psychology, 42, 116-131. https://doi.org/10.1037/0022-3514.42.1.116

Cacioppo, J. T., Petty, R. E., \& Kao, C. F. (1984). The efficient assessment of need for cognition. Journal of Personality Assessment, 48, 306-307. https://doi.org/10.1207/s15327752jpa4803_13

Case, D. O., \& Given, L. M. (2016). Looking for information: A survey of research on information seeking, needs, and behavior (4th ed.). Bingley, UK: Emerald. https://doi.org/10.1108/S2055-53772016022

Cin, S. D., Zanna, M. P., \& Fong, G. T. (2004). Narrative persuasion and overcoming resistance. In E. S. Knowles \& J. A. Linn (Eds.), Resistance and persuasion (pp. 175-191). Mahwah, NJ: Erlbaum.

Crowley, A. E., \& Hoyer, W. D. (1994). An integrative framework for understanding two-sided persuasion. Journal of the Royal Statistical Society (Series B), 39(1), 1-38. https://doi.org/10.1086/209370

Eisend, M. (2006). Two-sided advertising: A meta-analysis. International Journal of Research in Marketing, 23, 187-198. https://doi.org/10.1016/j.ijresmar.2005.11.001

Eisend, M. (2010). Explaining the joint effect of source credibility and negativity of information in two-sided messages. Psychology \& Marketing, 27(11), 1032-1049. https://doi.org/10.1002/mar.20372

Eisend, M., \& Tarrahi, F. (2022). Persuasion knowledge in the marketplace: A meta-analysis. Society for Consumer Psychology, 32(1), 3-22. https://doi.org/10.1002/jcpy.1258

Ertz, M., Jo, M-S., Karakas, F., \& Sarigöllü, E. (2021). Message sidedness effects in advertising: The role of Yin-Yang balancing theory. Social Sciences, 10(6), 1-26. https://doi.org/10.3390/socsci10060229

Green, M. C., \& Brock, T. C. (2000). The role of transportation in the persuasiveness of public narratives. Journal of Personality and Social Psychology, 79(5), 721. https://doi.org/10.1037//0022-3514.79.5.701

Green, M. C., \& Fitzgerald, K. (2017). Transportation theory applied to health and risk messaging. In J. Nussbaum (Ed.), Oxford Research Encyclopedia of Communication. Oxford: Oxford University Press. https://doi.org/10.1093/acrefore/9780190228613.013.261 
Hassanein, K., \& Head, M. (2007). Manipulating social presence through the Web interface and its impact on attitude towards online shopping. International Journal of Human-Computer Studies, 65(8), 689-708. https://doi.org/10.1016/j.ijhcs.2006.11.018

Haugtvedt, C. P., \& Petty, R. E. (1992). Personality and persuasion: Need for cognition moderated the persistence and resistance of attitude changes. Journal of Personality and Social Psychology, 63(2), 308-319. https://doi.org/10.1037/0022-3514.63.2.308

Haugtvedt, C. P., Petty, R. E., \& Cacioppo, J. T. (1992). Need for cognition and advertising: Understanding the role of personality variables in consumer behavior. Journal of Consumer Psychology, 1(3), 239-260. https://doi.org/10.1016/S1057-7408(08)80038-1

Hirsch, A. R. (1992). Nostalgia: A Neuropsychiatric understanding. In F. S. Jr. John \& S. Brian (Eds.), Advances in Consumer Research (Vol. 19, pp. 390-395). Provo, UT: Association for Consumer Research

Jones, E. E., \& Davis, K. E. (1965). From acts to dispositions: The attribution process in person perception. In L. Berkowitz (Ed.), Advances in experimental social psychology (pp. 219-266). New York: Academic Press. https://doi.org/10.1016/S0065-2601(08)60107-0

Jones, E. E., \& McGillis, D. (1976). Correspondent inferences and the attribution cube: A comparative reappraisal. In J. Harvey, W. J. Ickes \& R. F. Kidd (Eds.), New directions in attribution research (pp. 389-420). Hillsdale, NJ: Erlbaum

Karmarkar, U. R., \& Tormala, Z. L. (2010). Believe me, I have no idea what I'm talking about: The effects of source certainty on consumer involvement and persuasion. Journal of Consumer Research, 36, 1033-1049. https://doi.org/10.1086/648381

Kim, S. (2012). Does corporate advertising work in a crisis? An examination of inoculation theory. Journal of Marketing Communications, 19(4), 293-305. https://doi.org/10.1080/13527266.2011.634430

Knowles, E. S., \& Linn, J. A. (2004). The importance of resistance to persuasion. In S. Knowles \& J. A. Linn (Eds.), Resistance and persuasion (pp. 3-9). Mahwah, NJ: Erlbaum. https://doi.org/10.4324/9781410609816

Koenig, A. M., \& Eagly, A. H. (2014). Evidence for the social role theory of stereotype content: Observations of groups' roles shape stereotypes. Journal of Personality and Social Psychology, 107(3), 371-392. https://doi.org/10.1037/a0037215

Kuisma, J., Simola, J., Uusitalo, L., \& Oorni, A. (2010). The effects of animation and format on the perception and memory of online advertising. Journal of Interactive Marketing, 24, 269-282. https://doi.org/10.1016/j.intmar.2010.07.002

Levin, I., \& Gaeth, G. E. (1988). How consumers are affected by the framing of attribute information before and after consuming the product. Journal of Consumer Research, 15, 374-378. https://doi.org/10.1086/209174

Lin, S., \& Huang, Y. (2009). A study on college students' perception of English learning environment. Journal of National Taichung University of Education, 23(1), 153-173. http://ord221145.ntcu.edu.tw/

McGuire, W. J. (1964). Inducing resistance to persuasion: Some contemporary approaches. In L. Berkowitz (Ed.), Advances in experimental social psychology (pp. 191-229). New York: Academic Press. https://doi.org/10.1016/S0065-2601(08)60052-0

Nunnally, J. C. (1978). Psychometric theory (2nd ed.). New York: McGraw-Hill.

Pérez-Sobrino, P. (2016). Multimodal metaphor and metonymy in advertising: A corpus-based account. Metaphor and Symbol, 31(2), 73-90. https://doi.org/10.1080/10926488.2016.1150759

Petty, R. E., \& Cacioppo, J. T. (1986). Communication and persuasion: Central and peripheral routes to attitude change. New York: Springer Verlag. https://doi.org/10.1007/978-1-4612-4964-1

Petty, R. E., Cacioppo, J. T., \& Schumann, D. (1983). Central and peripheral routes to advertising effectiveness: The moderating role of involvement. The Journal of Consumer Research, 10(2), 135-146. https://doi.org/10.1086/208954

Petty, R. E., Cacioppo, J. T., Strathman, A. J., \& Priester, J. R., (2005). To think or not to think. In T. L. Brook \& M. C. Green (Eds.), Sage Persuasion: Psychological insights and perspectives. Thousand Oaks, CA: Sage.

Phillips, B. J., \& McQuarrie, E. F. (2010). Narrative and persuasion in fashion advertising. Journal of Consumer Research, 37(3), 368-392. https://doi.org/10.1086/653087 
Richins, M. L. (1997). Measuring emotions in the consumption experience. Journal of Consumer Research, 24(2), 127-146. https://doi.org/10.1086/209499

Sagarin, B. J., \& Serna, S. B. (2002). Dispelling the illusion of invulnerability: The motivations and mechanisms of resistance to persuasion. Journal of Personality and Social Psychology, 83(3), 526-541. https://doi.org/10.1037/0022-3514.83.3.526

Saine, R., Nguye, C. A., Besharat, A., \& Trocchia, P. J. (2018). To stay or switch: Breaking the habit of status quo through imagery perspective. European Journal of Marketing, 52(9/10), 1864-1885. https://doi.org/10.1108/EJM-03-2016-0188

Schmitt, J. B., Caspari, C., Wulf, T., Bloch, C., \& Rieger, D. (2021). Two sides of the same coin? The persuasiveness of one-sided vs. two-sided narratives in the context of radicalization prevention. SCM Studies in Communication and Media, 10(1), 48-71. https://doi.org/10.5771/2192-4007-2021-1-48

Strick, M., Holland, R. W., van Baaren, R. B., \& van Knippenberg, A. (2012). Those who laugh are defenseless: How humor breaks resistance to influence. Journal of Experimental Psychology, 18(2), 213-223. https://doi.org/10.1037/a0028534

Szybillo, G. J., \& Heslin, R. (1973). Resistance to persuasion: Inoculation theory in a marketing context. Journal of Marketing Research, 10(4), 396-403. https://doi.org/10.1177/002224377301000407

Tormala, Z. L., \& Petty, R. E. (2002). What doesn't kill me makes me stronger: The effects of resisting persuasion on attitude certainty. Journal of Personality and Social Psychology, 83(6), 1298-1313. https://doi.org/10.1037/0022-3514.83.6.1298

Tormala, Z. L., \& Petty, R. E. (2004). Resistance to persuasion and attitude certainty: The moderating role of elaboration. Personality and Social Psychology Bulletin, 30(11), 1446-1457. https://doi.org/10.1177/0146167204264251

Urminsky, O. (2017). The role of psychological connectedness to the future self in decisions over time. Current Directions in Psychological Science, 26(1), 34-39. https://doi.org/10.1177/0963721416668810

Vanwesenbeeck, I., Walrave, M., \& Ponnet, K. (2016). Children and advergames: The role of product involvement, prior brand attitude, persuasion knowledge and game attitude in purchase intentions and changing attitudes. International Journal of Advertising, 36(4), 520-541. https://doi.org/10.1080/02650487.2016.1176637

Volkman, J. E. (2017). Narratives in health and risk messaging. In J. Nussbaum (Ed.), Oxford Research Encyclopedia of Communication (pp. 1-24). Oxford: Oxford University Press. https://doi.org/10.1093/acrefore/9780190228613.013.306

Weinstein, E. A., \& Deutschberger, P. (1964). Tasks, bargains and identities in social interaction. Social Forces, 42, 451-456. https://doi.org/10.2307/2574989

Xu, M., \& Petty, R. E. (2021). Two-Sided messages promote openness for morally based attitudes. Personality and Social Psychology Bulletin, 1-16. https://doi.org/10.1177/0146167220988371

Yang, X., Huang, Y., Cai, X., Song, Y., Jiang, H., Chen, Q., \& Chen, Q. (2021). Using imagination to overcome fear: How mental simulation nudges consumers' purchase intentions for upcycled food. Sustainability, 13(3), 1-21. https://doi.org/10.3390/su13031130

Zhang, M., \& Aggarwal, P. (2015). Looking ahead or looking back: current evaluations and the effect of psychological connectedness to a temporal self. Journal of Consumer Psychology, 25(3), 512-518. https://doi.org/10.1016/j.jcps.2015.01.002

\section{Copyrights}

Copyright for this article is retained by the author, with first publication rights granted to the journal.

This is an open-access article distributed under the terms and conditions of the Creative Commons Attribution license (http://creativecommons.org/licenses/by/4.0/). 